\title{
A case report on contamination of zearalenone, fumonisins and 8- ketotrichothecenes possibly including iso-deoxynivalenol in moldy corn harvested in Korea
}

\author{
Hwang-Bae SoHN*1, Yin-Won LeE*1, Moon-Han LEE*2, and Takumi YoshizAWA*3 \\ (Received May. 21, 1998 ; Accepted July. 24, 1998)
孫 煌培*1, 李 仁遠*1, 李 文漢*2, 芳澤 宅實*3: 韓国で収穫されたカビトウモロコ シのイソデオキシニバレノールを含む可能性のある 8一ケトトリコテセン，ゼアラレノ ン，フモニシンによる污染例

\begin{abstract}
Summary
Five moldy corn samples were analyzed for Fusarium mycotoxins including 8ketotrichothecenes, zeralenone (ZEA), and fumonisins and found to be heavily contaminated with these toxins. Among 8-ketotrichothecenes, deoxynivalenol (DON), 15-acetyl-DON, and nivalenol (NIV) were the major toxins rather than 3-acetyl-DON and 4-acetyl-NIV. In addition, one moldy corn sample was contaminated with iso-DON, which has the same molecular weight of DON. This is the first report iso-DON and DON as well as other Fusarium mycotoxins were occurred in moldy corn from Korea.
\end{abstract}

Key words : trichothecene, iso-deoxynivalenol, fumonisins, zearalenone, moldy corn

\section{Introduction}

Corn is an imortant crop in Kangwon province, which is located in the mideastern part of Korea. Corn is used not only for animal feedstuffs but also used for a staple food with rice in the Kangwon province. It is sown in the early summer and harvested during the autumn. During the growing period, corn stalk and ear rot is often a serious problem in the Kangwon province. Although incidents of mycotoxicoses due to consumption of corn infected with Fusarium species have not been reported in this area, the natural occurrence of Fusarium mycotoxins such as deoxynivalenol (DON), 15acetyldeoxynivalenol (15-ADON), nivalenol (NIV), and zearalenone (ZEA) has been reported ${ }^{11}$. Several investigators $^{2,3)}$ also reported that Fusarium isolates from corn in this area were highly toxic to experimental animals and could produce trichothecenes and
ZEA. A period of prolonged rainy wheather during the fall of 1997 resulted in a delayed corn harvest and provided conditions favoring inoculum buildup of Fusarium species throughout the Kangwon provincce. The moldy corn samples were submitted to our laboratory by one farmer to analyze mycotoxins, so the initial research started. Damage by Fusarium species was characterized as a reddish pink discoloration. In this paper, we attempted to analyze Fusar. ium mycotoxins including 8-ketotrichothecenes, ZEA and fumonisins in moldy corn samples and we found that one of moldy corn samples was contaminated with iso-deoxynivalenol (iso-DON) with other trichothecenes as well as ZEA and fumonisins.

\section{Materials and Methods}

Standards Trichothecene mycotoxins, including DON, NIV, 15-ADON, 3-acetyldeoxynivalenol (3ADON), 4-acetylnivalenol (4-ANIV), and ZEA were

${ }^{* 1}$ Division of Applied Biology and Chemistry and Research Center for New Biomaterials in Agriculture

${ }^{* 2}$ College of Veterinary Medicine, Seoul National University, Suwon 441-744, Korea

*3 Department of Biochemistry and Food Science, Faculty of Agriculture, Kagawa University, Miki-cho, Kita-gun, Kagawa 761-07 
purchased from Wako Pure Chemical Industries, Ltd., Osaka. Fumonisins including fumonisin $B_{1}$ $\left(\mathrm{FB}_{1}\right)$, fumonisin $\mathrm{B}_{2}\left(\mathrm{FB}_{2}\right)$, and fumonisin $\mathrm{B}_{3}\left(\mathrm{FB}_{3}\right)$ were prepared in $\mathrm{T}$. Yoshizawa's laboratory.

Samples Five moldy corn samples of each sample weighing approximately $100 \mathrm{~g}$ were submitted to our laboratory to analyze Fusarium mycotoxins during the third week of October, 1997 through the Extension Service Center of Seoul National University. All samples were milled to $120-250$ mesh with a laboratory mill and at stored $-20^{\circ} \mathrm{C}$ before analyses.

Extraction and analysis Each sample was analyzed for 8-ketotrichothecenes, ZEA, and fumonisins according to the procedures described previously. Briefly, a ground corn sample was extracted with acetonitrile-water $(3: 1, \mathrm{v} / \mathrm{v})$ and, following filtration and concentration, applied onto a florisil column for trichothecenes ${ }^{4)}$ and $\mathrm{ZEA}^{5)}$ or onto a strong anion exchange cartridge for fumonisins ${ }^{6}$. A portion of each extract was reacted with trimethylsilylating reagent and analyzed with a Shimadzu QP-5000 gas chromatograph-mass spectrometer (GC-MS) with a selected ion monitoring (SIM) mode. The calculation of trichothecene concentration was based on the average area counts of the fragment ions of each standard toxin by using SIM mode. The analytical conditions were as follows ; column, DB- 5 fused silica column $(30 \mathrm{~m} \times 0.25 \mathrm{~mm}$ id, $0.25 \mu \mathrm{m}$ film thickness, J \& W Scientific, CA, U.S.A.), column temperature, $120^{\circ} \mathrm{C}$ for $5 \mathrm{~min}$ and then increased to $270^{\circ} \mathrm{C}$ at $8^{\circ} \mathrm{C} /$ min ; injector temperature, $280^{\circ} \mathrm{C}$; ion source temperature, $200^{\circ} \mathrm{C}$, interface temperature, $250^{\circ} \mathrm{C}$; ionizing voltage, $70 \mathrm{eV}$. The fragment ions for quantitation of trichothecenes were $m / z 422$ and 393 for DON, $m$ / $z 392$ and 350 for 15-ADON, $m / z 377$ and 287 for 3-ADON, $m / z 379$ and 289 for NIV, and $m / z 480$ and 450 for 4-ANIV. Confirmation of trichothecenes was done by scan mode. ZEA was analyzed by high performance liquid chromatography (HPLC) with fluorescence detection. The excitation wavelength and emission wavelength of ZEA were $236 \mathrm{~nm}$ and $418 \mathrm{~nm}$, respectively. Fumonisins including $\mathrm{FB}_{1}$, $\mathrm{FB}_{2}$, and $\mathrm{FB}_{3}$ were derivatized by reacting with o-phthaldialdehyde and quantified by HPLC with fluorescence detection. The excitation wavelength and emission wavelength of fumonisins were $335 \mathrm{~nm}$ and $440 \mathrm{~nm}$, respectively.

\section{Results and Discussion}

All five samples were highly contaminated with 8-ketotrichothecenes, ZEA, and fumonisins. Among trichothecenes, DON, 15-ADON, and NIV were the major toxins at levels ranging from 1,600 to 15,000 $\mathrm{ng} / \mathrm{g}, 140$ to $2,700 \mathrm{ng} / \mathrm{g}$, and 94 to $4,300 \mathrm{ng} / \mathrm{g}$, respectively. $\mathrm{ZEA}$ and fumonisins including $\mathrm{FB}_{1}, \mathrm{FB}_{2}$, and $\mathrm{FB}_{3}$ were coincidently found at high levels with trichothecenes. Of the 5 samples, 3 corn samples were contaminated with DON and/or $\mathrm{FB}_{1}$ at levels of over $10 \mu \mathrm{g} / \mathrm{g}$.

Confirmation of 8-ketotrichothecenes in moldy corn extracts was done by scan mode using the silylated sample extracts. The retention time for each trichothecene was $21.22 \mathrm{~min}$ for $\mathrm{DON}, 22.38 \mathrm{~min}$ for $3-\mathrm{ADON}, 22.51 \mathrm{~min}$ for 4 -ANIV, $22.59 \mathrm{~min}$ for

Table 1 Occurrence of 8-ketotrichothecenes, zearalenone, and fumonisins in moldy corn

\begin{tabular}{crrrrrrrrr}
\hline \hline \multirow{2}{*}{$\begin{array}{c}\text { Sample } \\
\text { Code }\end{array}$} & \multicolumn{8}{c}{ Concentration (ng/g) of } \\
\cline { 2 - 10 } & DON & 15-ADON & 3-ADON & NIV & 4-ANIV & ZEA & \multicolumn{1}{c}{$\mathrm{FB}_{1}$} & \multicolumn{1}{c}{$\mathrm{FB}_{2}$} & $\mathrm{FB}_{3}$ \\
\hline 1 & 12,000 & 2,700 & 34 & 3,400 & 2.0 & 570 & 10,000 & 4,000 & 440 \\
2 & 15,000 & 1,400 & 87 & 4,300 & 140 & 7,300 & 12,000 & 440 & 160 \\
3 & 1,600 & 140 & $\mathrm{ND}^{\mathrm{a})}$ & 580 & 180 & 400 & 38,000 & 21,000 & 420 \\
4 & 1,100 & 1,700 & 16 & 94 & ND & 130 & 3,400 & 860 & 530 \\
5 & 6,300 & 30 & 51 & 1,400 & 11 & 1,500 & 5,200 & 700 & 320 \\
\hline
\end{tabular}

Trichothecenes were quatified by GC-MS with SIM mode, and ZEA and fumonisins were quantified by HPLC with fluorescence detection.

a) Not detected 

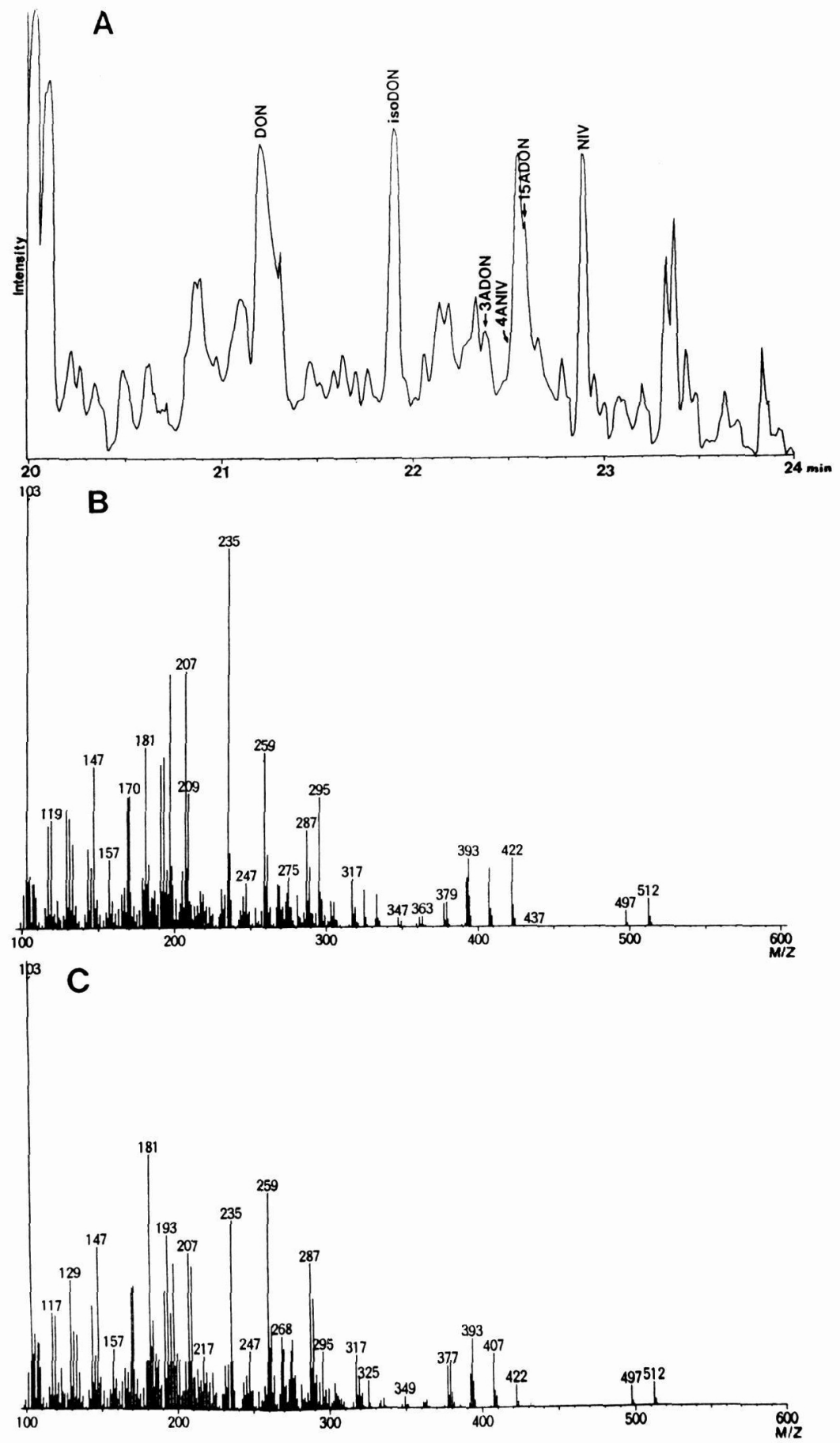

Fig. 1 Total ion chromatogram of trimethylsilyl (TMS) ethers of moldy corn extract (A) and mass spectra of TMS ethers of DON (B) and iso-DON (C) from the sample extract. 
15-ADON, and $22.90 \mathrm{~min}$ for NIV. Figure $1 \mathrm{~A}$ shows the total ion chromatogram of trimethylsilyl ethers of one of sample extracts (Sample code No. 2). The agreement of retention times coupled with the presence of diagnostic ions verified the presence of DON, 15-ADON, 3-ADON, NIV, and 4-ANIV in the sample extract. Figure 1B shows the mass spectrum of DON part of chromatogram. The mass spectrum of DON gave the diagnostic ions at $m / z 422,393,295$, 287, 259, 235 and the molecular ion at $m / z 512$. The GC-MS analysis of the extract also showed the peak other (retention time ; $21.91 \mathrm{~min}$ ) than DON to have a molecular ion at $m / z 512$ and the major fragment ions were same with those of DON, indicating that this compound is an isomer of DON (Figure 1C). The level of iso-DON in moldy corn was $1,600 \mathrm{ng} / \mathrm{g}$ by extraporating the calibration of DON. The extract was chromatographed on a preparative thin layer chromatography plate with DON standard and developed in chloroform-metahnol $(9: 1, \mathrm{v} / \mathrm{v})$. The regions corresponding to DON $\left(\mathrm{R}_{\mathrm{f}} ; 0.30\right)$ and iso-DON $\left(\mathrm{R}_{\mathrm{f}} ; 0.27\right)$ were scraped off, eluted with acetone, and concentrated to dryness. The residues were analyzed with a JEOL AX 505 GC-MS with a direct inlet. Figure $2 \mathrm{~A}$ and $2 \mathrm{~B}$ show the mass spectra of DON and iso-DON from the moldy corn extract, respectively. Both compounds have a molecular ion at $m / z 296$.

DON was found from the culture extract of $F$.
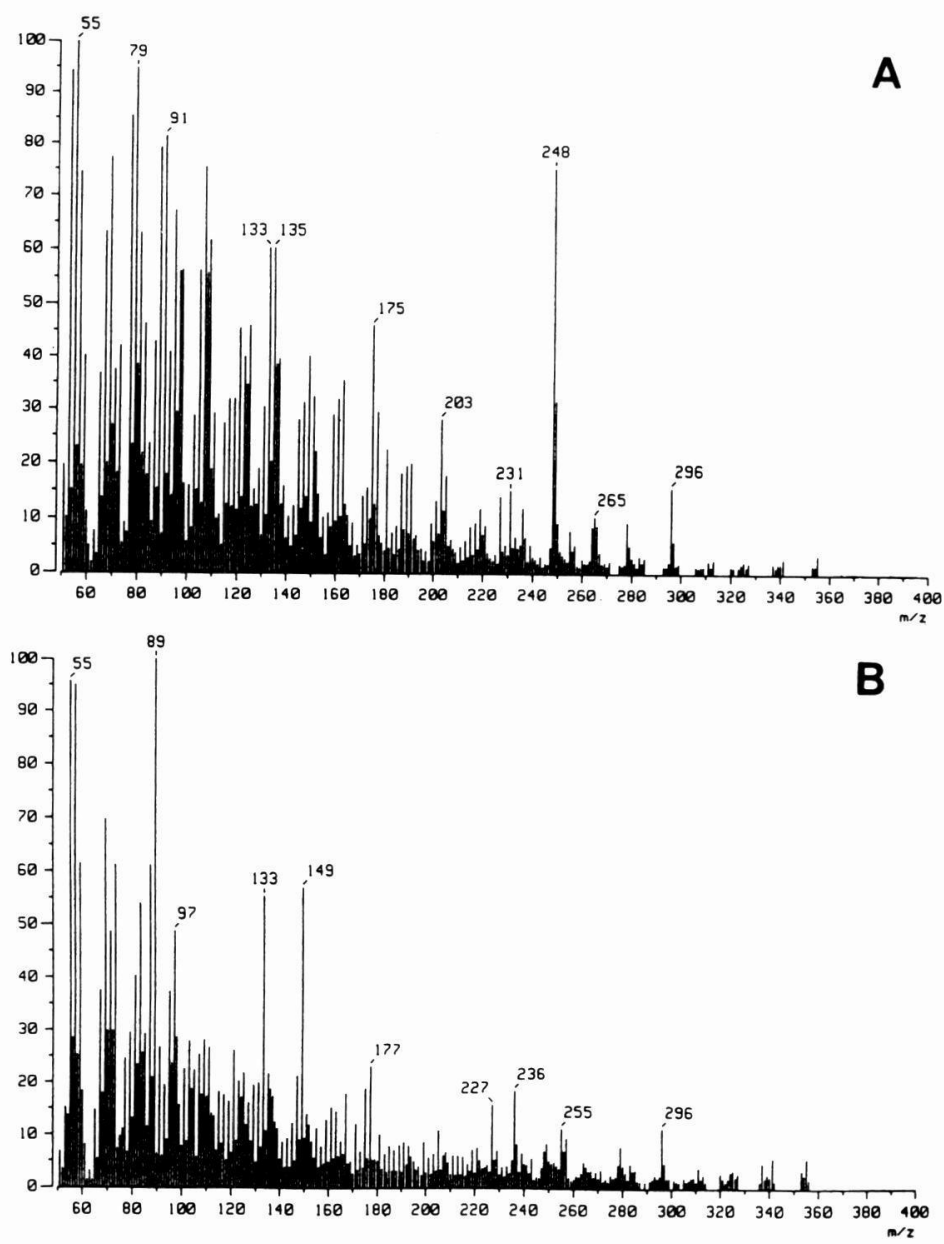

Fig. 2 Mass spectra of DON (A) and iso-DON (B) from the sample extract. 
roseum and moldy barley ${ }^{7)}$ and also reported as vomitoxin as the emetic principle from Fusarium infected $\operatorname{corn}^{8)}$. As for the natural occurrence of DON isomer, Vesonder et al. ${ }^{9)}$ isolated DON and DON isomer as the refusal and emetic principle from Fusarium infected corn samples. Compared mass spectrum of DON to DON isomer, there was no major ion $\mathrm{m} / z 248$ corresponding to the loss of both water and formaldehyde for the hydroxyl group adjacent to the C-keto group. They proposed DON isomer as DON with the hydroxyl group on the $\mathrm{C} 4$ position rather than $\mathrm{C} 7$ position. However, there is so far no evidence supporting this structure of 7 . hydroxy-DON.

The mass spectrum of iso-DON in this study is somewhat similar to that of DON isomer reported by Vesonder et al.9 ; no major ion at $m / z 248$ and major ions at $m / z 133$ and 117 were observed. At this moment, it is not definitely conclusive that both compounds are identical. Further studies could not be carried out to clarify the two compounds because of limited amounts of iso-DON. Mycological survey and production of 8-ketotrichothecenes by $F$. graminearum isolates from corn samples are in progress.
Acknowledgement This work was supported by a grant from Rural Development Administration of Korea.

\section{References}

1) Kim, J. -C., Kang, H. -J., Lee, D. -H., Lee Y. -W., Yoshizawa, T.: Appl. Environ. Microbiol., 59, 3798-3802 (1993).

2) Kim, K. -H., Lee, Y. -W., Mirocha, C. J., Pawlosky R. J. : Appl. Environ. Microbiol., 56, 260-263 (1990).

3) Lee, Y-W., Kim, K. -H., Chung, H. -S. : Kor. J. Mycol., 18, 13-19 (1990).

4) Tanaka, T., Hasegawa, A., Matsuki, Y., Ishii, K., Ueno, Y.: Food Addit. Contam., 2, 125-137 (1985).

5) Tanaka, T., Hasegawa, A., Yamamoto, S., Lee, U. -S., Sugiura, Y., Ueno, Y.: J. Agric. Food Chem., 36, 979-983 (1986).

6) Yoshizawa, T., Yamashita, A., Chokethaworn, N. : Food Addit. Contam., 13, 163-168 (1996).

7) Yoshizawa, T., Morooka, N.: Agric. Biol. Chem., 37, 2933-2934 (1973).

8) Vesonder, R. F., Ciegler, A., Jensen, A. H.: Appl. Microbiol., 25, 1008-1010 (1973).

9) Vesonder, R. F., Ciegler, A., Jensen, A. H., Rothwedder, W. K., Weisleder, D.: Appl. Envrion. Microbiol., 31, 280-285 (1976). 